\title{
EVALUACIÓN DE DAÑO AL ADN EN LEUCOCITOS DE SANGRE PERIFÉRICA HUMANA EXPUESTOS AL HERBICIDA GLIFOSATO
}

\author{
María Carolina BARBOSA ${ }^{1}$, Delia AIASSA ${ }^{2 *}$ y Fernando MAÑAS ${ }^{3}$
}

${ }^{1}$ Consejo Nacional de Investigaciones Científicas y Técnicas, Universidad Nacional de Cuyo. Avenida Champagnat 5500, Mendoza, Argentina,

2 Departamento de Ciencias Naturales, Universidad Nacional de Río Cuarto. Ruta 6, kilómetro 601, Río Cuarto, Córdoba, Argentina

${ }^{3}$ Farmacología, Facultad de Agronomía y Veterinaria, Universidad Nacional de Río Cuarto. Ruta 6, kilómetro 601, Río Cuarto, Córdoba, Argentina

*Autor para correspondencia: delia.aiassa@gmail.com

(Recibido junio 2016; aceptado diciembre 2016)

Palabras clave: genotoxicidad, plaguicidas, ensayos in vitro

\section{RESUMEN}

Argentina es el principal exportador mundial de aceite y harina de soja, y el tercer proveedor mundial de la oleaginosa en grano. La superficie total cultivada con soja creció alrededor del $50 \%$ en los últimos 30 años, ocupando la mitad del área sembrada del país y con esto el uso de numerosos plaguicidas. Uno de los problemas del empleo de plaguicidas es el posible impacto sobre las poblaciones humanas expuestas directa o indirectamente. De aquí la importancia de evaluar el potencial genotóxico de estas sustancias a través de biomarcadores como aberraciones cromosómicas, micronúcleos, intercambio de cromátidas hermanas o el ensayo cometa. En este estudio se evaluó el potencial genotóxico de una formulación comercial de glifosato (glifosato II-Atanor ${ }^{\circledR}$, glifosato $43.8 \%$ ) por medio del ensayo cometa y se determinó la concentración de especies reactivas al ácido tiobarbitúrico (TBARS), para cuantificar la peroxidación lipídica, proceso que ocurre bajo condiciones de estrés oxidante. Todas las concentraciones de glifosato en formulación comercial produjeron un aumento estadísticamente significativo del momento de la cola respecto al testigo negativo. Se halló una correlación entre el aumento de la lipoperoxidación y la fragmentación de ADN medida como el momento de la cola, por lo que se estima que el estrés oxidante podría ser uno de los principales factores que estarían alterando el funcionamiento normal de las células, entendiéndose a este proceso como la principal consecuencia de una exposición a glifosato.

Key words: genotoxicity, pesticides, in vitro tests

\begin{abstract}
Argentina is the world's largest exporter of oil and soybean flour, and the third largest supplier of the oleaginous grain. The total area planted with soybean grew about $50 \%$ in the past 30 years, occupying half the planted area in the country and thus the use of many pesticides. One of the problems of pesticide use is the possible impact on
\end{abstract}


human populations exposed directly or indirectly. Hence the importance of assessing the genotoxic potential of these substances through biomarkers as chromosomal aberrations, micronuclei, sister chromatid exchange or comet assay. This study evaluated the genotoxic potential of a glyphosate commercial formulation (glyphosate II-Atanor ${ }^{\circledR}$, glyphosate $43.8 \%$ ) by the comet assay and the concentration of thiobarbituric acid reactive species (TBARS) was determined to quantify the lipid peroxidation process that occurs under oxidative stress. All concentrations of glyphosate in commercial formulation produced a statistically significant increase in tail moment relative to negative control. A correlation between increased lipid peroxidation and DNA fragmentation measured as the tail moment was found, so it is estimated that oxidative stress might be one of the main factors that would disrupt the normal functioning of cells, being understood this process as the main consequence of exposure to glyphosate.

\section{INTRODUCCIÓN}

Argentina es el principal exportador mundial de aceite y harina de soja y el tercer proveedor mundial de la oleaginosa en grano (FAO 2013). La superficie total cultivada con soja creció alrededor del $50 \%$ en los últimos 30 años, ocupando la mitad del área sembrada del país (GEA 2013).

Sumado a este incremento de las superficies cultivadas de soja en detrimento de otros cultivos y de la producción láctea, en las últimas décadas se ha provocado un crecimiento notable de los volúmenes de plaguicidas empleados, especialmente del herbicida glifosato (Vila-Aiub et al. 2008, Di Fiori et al. 2012).

Uno de los problemas del uso de plaguicidas es el posible impacto sobre las poblaciones humanas expuestas directa o indirectamente a la acción de estos agentes tóxicos. Los plaguicidas, al igual que muchas otras sustancias químicas, son potenciales generadores de daño genético. En esa dirección, existe suficiente evidencia basada en consideraciones mecanísticas para afirmar que los agentes genotóxicos son potencialmente cancerígenos, y se ha establecido una correlación positiva entre individuos expuestos a estas sustancias, ya sea de forma ocupacional o accidental, y el incremento del riesgo de padecer cáncer (De Marini et al. 1989, IARC 1991, Solans y Hernández 2000, Bolognesi 2003).

Todas las poblaciones tienen, en mayor o menor grado, riesgo de exposición a plaguicidas, ya sean los de uso agrícola, los que se utilizan en otro ámbito e incluso mediante residuos químicos en los alimentos (Sailaja et al. 2006). De aquí la importancia de evaluar el potencial genotóxico de estas sustancias a través de biomarcadores como aberraciones cromosómicas, micronúcleos, intercambio de cromátidas hermanas o el ensayo cometa (Aiassa et al. 2012).

El ensayo cometa es un método sencillo, rápido y de alta sensibilidad para detectar niveles bajos de daño al ADN en células individuales. En la última década ha sido un método para evaluar a nivel de $\mathrm{ADN}$, con aplicaciones en epidemiología molecular y monitoreo humano, comprobación de genotoxicidad, ecotoxicología, así como en la investigación básica de daño y reparación del ADN (Collins et al. 2004).

Asimismo, el efecto tóxico en la mayoría de los plaguicidas es causado mediante mecanismos de estrés oxidante, produciéndose la alteración del estado de reducción oxidación (redox), según Astiz et al. (2009).

El glifosato es el principio activo de Roundup ${ }^{\circledR}$, el herbicida de amplio espectro post-emergencia más empleado en todo el mundo. En la Argentina se utilizan casi 200 millones de L de distintas formulaciones de glifosato sobre unas 19 millones de hectáreas por año, principalmente asociadas al cultivo de soja transgénica (Paganelli et al. 2010). La preocupación en gran parte de la comunidad científica en la actualidad, se centra en los efectos que la exposición al glifosato, y fundamentalmente a cualquiera de sus formulaciones comerciales pudiera tener en la salud animal y humana a largo plazo, incluyendo el potencial genotóxico de este plaguicida. En este sentido, los resultados obtenidos por el grupo de Robert Bellé, demuestran que Roundup ${ }^{\circledR}$ y otras formulaciones comerciales conteniendo glifosato podrían representar un riesgo a largo plazo debido a su capacidad de producir una disfunción de la división celular, retrasando la activación del complejo ciclina B/CDK1. Los autores sostienen que estas alteraciones en el control del ciclo celular llevan a una inestabilidad genómica que podría resultar en el desarrollo de una neoplasia a partir de la célula afectada (Marc et al. 2002, 2003 y 2004). Asimismo, la capacidad del herbicida glifosato de interactuar con el material genético ha sido reportada por una gran cantidad de investigadores en todo el mundo en diversos diseños experimentales, in vivo 
e in vitro (Rank et al. 1993, Bolognesi et al. 1997, Benachour et al. 2007, Lioi et al. 1998, Monroy et al. 2005, Mañas et al. 2006, Paz-y-Miño et al. 2007, Mañas et al. 2009a, Mañas et al. 2009b). Es importante resaltar que el potencial de una sustancia para inducir el desarrollo neoplásico podría relacionarse a la capacidad de la misma para actuar sobre el material genético en forma adversa, es decir a su genotoxicidad (Albertini et al. 2008).

Si bien algunos autores reportan alteraciones en el balance oxidante causadas por la exposición a glifosato o alguna de sus formulaciones comerciales (Astiz et al. 2009, Beuret et al. 2005, El-Shenawy 2009), existen pocas investigaciones sobre la relación entre exposición a glifosato y generación de estrés oxidante, y mucho menos la participación de la injuria oxidante en la génesis del daño genético.

En este estudio se evaluó el potencial genotóxico de una formulación comercial de glifosato (glifosato II-Atanor ${ }^{\circledR}$, glifosato $43.8 \%$ ) por medio del ensayo cometa, y se determinó la concentración de especies reactivas al ácido tiobarbitúrico (TBARS), para cuantificar la peroxidación lipídica, proceso que ocurre bajo condiciones de estrés oxidante.

\section{MATERIALES Y MÉTODOS}

\section{Ensayo cometa en leucocitos humanos Obtención de las muestras de sangre}

Se obtuvo sangre periférica de tres donadores sanos de 24, 27 y 30 años, no fumadores, sin exposición laboral a agroquímicos, sin tratamiento médico, ni exposición a rayos $\mathrm{X}$ en los últimos nueve meses, previo consentimiento informado, el cual fue aprobado por el Comité de Ética del Instituto Multidisciplinario de Biología Celular de la ciudad de La Plata y de la Universidad Nacional de Río Cuarto (Exp. 03/13), en el marco del proyecto Código 18/ C377, Resol Rec. 852/11. La extracción la realizó un profesional habilitado (bioquímica), mediante punción venosa con una jeringa estéril heparinizada.

\section{Exposición de la sangre a glifosato II (Atanor®)}

Con base en las concentraciones utilizadas por Mañas et al. (2009a, b) para glifosato puro, se realizaron ensayos previos para determinar la citotoxicidad y viabilidad de los leucocitos. Se decidió utilizar tres concentraciones finales de glifosato en formulación comercial (glifosato II Atanor ${ }^{\circledR}$ ): $37.5,75$ y $112.5 \mu \mathrm{g} / \mathrm{mL}$ en amortiguador de fosfato salino (PBS, por sus siglas en inglés) como disolvente. En dichas formulaciones comerciales la viabilidad determinada mediante coloración con azul tripano (Freshney 2000), fue mayor a $95 \%$. Las concentraciones varían entre 56 y 170 veces menos que las recomendadas para pulverizaciones aéreas por la empresa que produce el herbicida.

Cada muestra de sangre se fraccionó en cinco tubos estériles de vidrio en un volumen de $2 \mathrm{~mL}$. Posteriormente, a cada tubo se añadieron las concentraciones seleccionadas: $37.5,75$ y $112.5 \mu \mathrm{g} / \mathrm{mL}$ de la formulación comercial en PBS. Se utilizó PBS como testigo negativo. Como testigo positivo se empleó una solución de peróxido de hidrógeno $20 \mu \mathrm{M}$. Los tubos se incubaron en estufa a $37^{\circ} \mathrm{C}$ durante 4 horas con agitador orbital.

\section{Aislamiento de leucocitos de sangre periférica humana}

Transcurrida la incubación, se separó el plasma mediante centrifugación para realizar el ensayo de TBARS, y se procedió a aislar leucocitos del paquete globular mediante la lisis de los eritrocitos según Brendler-Shwaab et al. (1994) con algunas modificaciones. Una vez logrado el aislamiento de los leucocitos se cuantificó la viabilidad celular mediante el ensayo de coloración con Azul de Tripano (Freshney, 2000).

\section{Ensayo cometa}

El ensayo fue realizado siguiendo el protocolo descripto por Singh et al. (1988) con algunas modificaciones. Se mezclaron $250 \mu \mathrm{L}$ de agarosa de bajo punto de fusión (Promega) con $50 \mu \mathrm{L}$ de la solución de leucocitos, cuya concentración fue de $3 \times 10^{6}$ células $/ \mathrm{mL}$ aproximadamente. De esa mezcla se colocaron $65 \mu \mathrm{L}$ en un portaobjetos previamente embebido con $200 \mu \mathrm{L}$ de agarosa de punto de fusión normal (Biodynamics). Los portaobjetos se colocaron cuidadosamente en jarras Coplin conteniendo solución de lisis y se llevaron a $4{ }^{\circ} \mathrm{C}$ en heladera al menos durante una hora. Posteriormente se procedió a transferir los portaobjetos a una cubeta de electroforesis, que contenía una solución alcalina fría a $\mathrm{pH} 13$ y se los dejó 20 min aproximadamente. A continuación, se llevó a cabo la corrida electroforética durante $30 \mathrm{~min}$ a 30 V y $250 \mathrm{~mA}$ utilizando la misma solución. Luego, se neutralizaron los portaobjetos, procedimiento realizado tres veces con intervalos de $5 \mathrm{~min}$. Por último, los portaobjetos se colorearon con $40 \mu \mathrm{L}$ de bromuro de etidio a una concentración de $20 \mu \mathrm{g} / \mathrm{mL}$ y de inmediato se analizaron al microscopio óptico de fluorescencia. Todas las muestras se procesaron por duplicado, preparando por lo tanto dos réplicas por cada tratamiento. 


\section{Análisis de imágenes}

Un total de 100 células se observaron al microscopio óptico de fluorescencia con un aumento de 400x. En oscuridad, se tomaron fotografías de cada una de las células y las imágenes obtenidas fueron analizadas mediante el programa Comet Score 1.5®. El parámetro elegido para evaluar el daño al ADN fue el momento de la cola. Los cometas sin núcleo detectable o "nubes" no fueron considerados en el análisis. Los resultados se transfirieron automáticamente a una planilla Excel con el parámetro seleccionado (Mañas et al. 2009a, b).

Evaluación del estrés oxidante mediante la cuantificación de sustancias reactivas al ácido tiobarbitúrico (TBARS)

Se procedió a determinar las sustancias reactivas al ácido tiobarbitúrico mediante el método descrito por Buege y Aust (1978), modificado por Marcinčák et al. (2003) en plasma de sangre periférica humana. Éste se obtuvo luego de la primera centrifugación de la sangre expuesta a los distintos tratamientos para la realización del ensayo cometa (previo al aislamiento de linfocitos) y se conservó a $-20^{\circ} \mathrm{C}$ hasta la cuantificación de TBARS.

Se utilizó malondialdehído (MDA) como sustancia de referencia, obtenida a partir de la hidrólisis de $400 \mu \mathrm{L}$ de 1,2,3,3-tetrametoxipropano (TMP, Cicarelli), luego de su incubación con $216 \mu \mathrm{L}$ de $\mathrm{HCl}$ (1 M, Merck) en un tubo a baño María durante 30 min a $37^{\circ} \mathrm{C}$. A partir de esa mezcla se realizaron las diluciones apropiadas hasta obtener las concentraciones de 1.83, $3.66,7.32,14.63,29.67$ y $58.54 \mathrm{nmol} / \mathrm{mL}$, adecuadas para realizar la curva de calibración necesaria para efectuar los cálculos de las concentraciones de MDA de cada uno de los plasmas.

Se colocaron $500 \mu \mathrm{L}$ de ácido tricloroacético (TCA, Cicarelli) al $15 \%$ en 15 tubos, cinco para cada donador. A continuación, se añadió $20 \mu \mathrm{L}$ de agua destilada y $500 \mu \mathrm{L}$ de ácido tiobarbitúrico (TBA,
Cicarelli) al $0.375 \%$. Luego, se mezclaron $250 \mu \mathrm{L}$ de plasma con $250 \mu \mathrm{L}$ de agua destilada y se los colocó en la solución anteriormente preparada. Se incubó a $90{ }^{\circ} \mathrm{C}$ durante 30 min y se acomodaron en un congelador a $-20^{\circ} \mathrm{C}$ durante $10 \mathrm{~min}$. Posteriormente, se agregaron $1800 \mu \mathrm{L}$ de butanol bajo una campana de extracción de gases e inmediatamente se centrifugó durante 10 min a $3500 \mathrm{rpm}$. Finalmente se realizaron las lecturas por triplicado en el espectrofotómetro a 510,532 y $560 \mathrm{~nm}$. Se aplicó la siguiente fórmula con objeto de disminuir la interferencia provocada por diversos hemopigmentos como la hemoglobina (de Sousa Sá et al. 2013): MDA532 = 1.22 [(A532) $-(0.56)(\mathrm{A} 510)+(0.44)(\mathrm{A} 560)]$. Los niveles de lipoperoxidación se expresan como nmol de MDA/ $\mathrm{mL}$ de plasma.

\section{Análisis estadístico}

El supuesto de normalidad fue evaluado mediante la prueba de Kolmogorov-Smirnov. Para los datos que siguieran una distribución normal, se realizó un análisis de la varianza con el fin de evaluar las diferencias entre los distintos tratamientos, seguido de la prueba de comparaciones múltiples de Dunnett. En el caso de que los datos no siguieran una distribución normal, se procedió a realizar la prueba de Kruskal-Wallis y la prueba a posteriori de Dunn para comparaciones múltiples no paramétricas. El coeficiente de Pearson se utilizó para determinar la relación existente entre los distintos parámetros analizados. Se emplearon los programas Prism 3.0 (Prism 1997) y Statgraphics Plus 5.1 (Statgraphics 1992).

\section{RESULTADOS}

En la cuadro I se resumen los valores obtenidos mediante el ensayo cometa para el parámetro seleccionado (momento de la cola) como medida de daño

CUADRO I. ENSAYO COMETA: MOMENTO DE LA COLA PARA TRES CONCENTRACIONES DE LA FORMULACIÓN COMERCIAL GLIFOSATO II (ATANOR®)

\begin{tabular}{|c|c|c|c|c|c|}
\hline $\begin{array}{l}\text { Tratamiento } \\
\mu \mathrm{g} / \mathrm{mL}\end{array}$ & Donador 1 & Donador 2 & Donador 3 & $\begin{array}{l}\text { Media por } \\
\text { tratamiento }\end{array}$ & $\mathrm{p}$ \\
\hline Testigo negativo & $921.4 \pm 93.82$ & $2067 \pm 211.3$ & $519.5 \pm 84.6$ & $1169.3 \pm 129.90$ & \\
\hline Glifosato 37.5 & $1870 \pm 169.3$ & $2152 \pm 151.4$ & $1333 \pm 106.2$ & $1785 \pm 142.3$ & $* * *$ \\
\hline Glifosato 75 & $2207 \pm 230.8$ & $2190 \pm 231.6$ & $1453 \pm 127.8$ & \pm 196.73 & $* * *$ \\
\hline Glifosato 112.5 & $2558 \pm 195.8$ & $2480 \pm 424.5$ & $1410 \pm 188.6$ & $2149.33 \pm 269.63$ & $* * *$ \\
\hline Testigo positivo & $1968 \pm 193.8$ & $1216 \pm 138.5$ & $2350 \pm 149.1$ & $1844.66 \pm 160.46$ & $* * *$ \\
\hline
\end{tabular}

Valores expresados como promedio \pm error estándar. $* * *=\mathrm{p}<0.001$. Prueba de Dunn luego de realizar una prueba de Kruskal-Wallis para datos no paramétricos 
inducido en el ADN. Todas las concentraciones de glifosato en formulación comercial produjeron un aumento estadísticamente significativo del momento de la cola respecto al testigo negativo (Fig. 1).

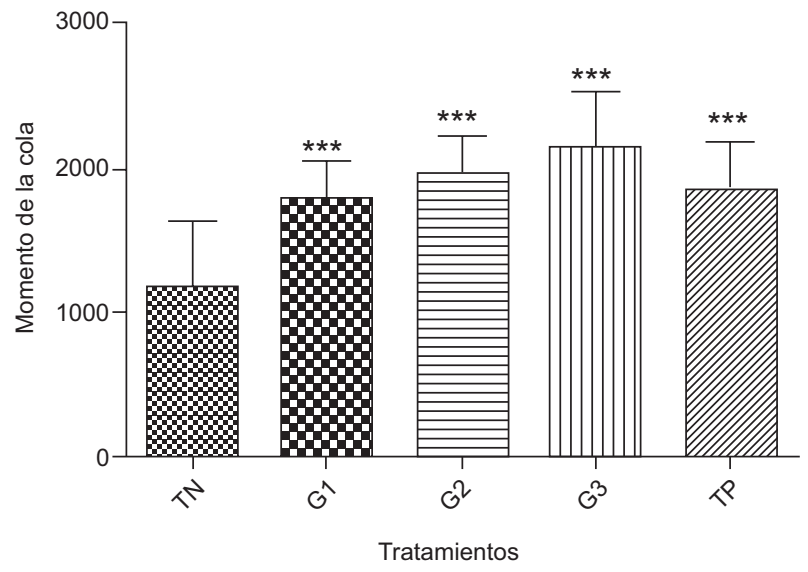

Fig. 1. Niveles alcanzados de daño al ADN en células sanguíneas humanas expuestas a distintas concentraciones de glifosato. $\mathrm{TN}=$ testigo negativo, $\mathrm{G} 1=37.5 \mu \mathrm{g} / \mathrm{mL}$ de glifosato, $\mathrm{G} 2=75 \mu \mathrm{g} / \mathrm{mL}$ de glifosato, $\mathrm{G} 3=112.5 \mu \mathrm{g} / \mathrm{mL}$ de glifosato II (Atanor $\AA)$. TP = testigo positivo $(20 \mu \mathrm{M}$ de $\left.\mathrm{H}_{2} \mathrm{O}_{2}\right)$, *** $=\mathrm{p} \leq 0.001$, Prueba de Dunn, luego de realizar una prueba de Kruskal-Wallis

Se observó una correlación positiva entre el momento de la cola y las distintas concentraciones de glifosato, con un $r=0.9342$ y $p=0.043$ para el coeficiente de correlación de Pearson (Fig. 2).

En la figura 3 se presentan los valores correspondientes a la determinación de sustancias reactivas al

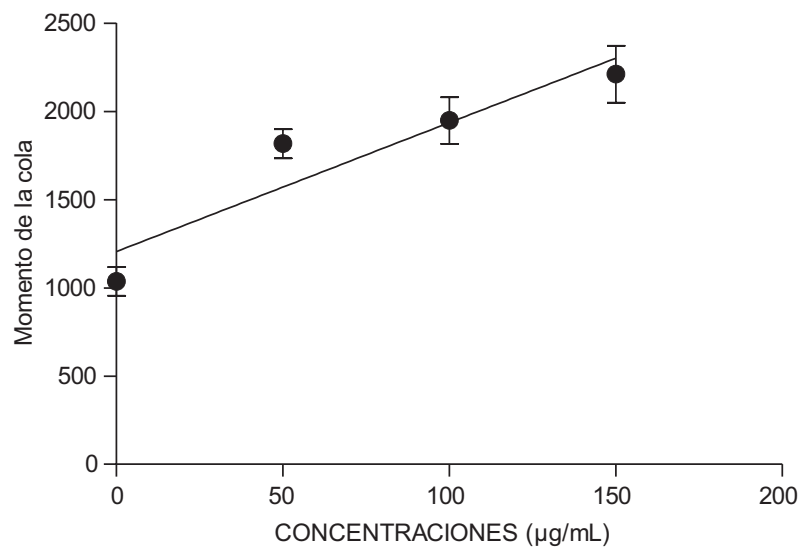

Fig. 2. Relación concentración unidades arbitrarias de daño al ADN tras exposición a distintas concentraciones $(\mu \mathrm{g} / \mathrm{mL})$ de la formulación comercial de glifosato II (Atanor $\left.{ }^{\circledR}\right)$. Coeficiente de correlación $\mathrm{r}=0.9342, \mathrm{p}=0.0329$, prueba de Pearson. ácido tiobarbitúrico (TBARS) en plasma de sangre periférica humana expuesta a glifosato.

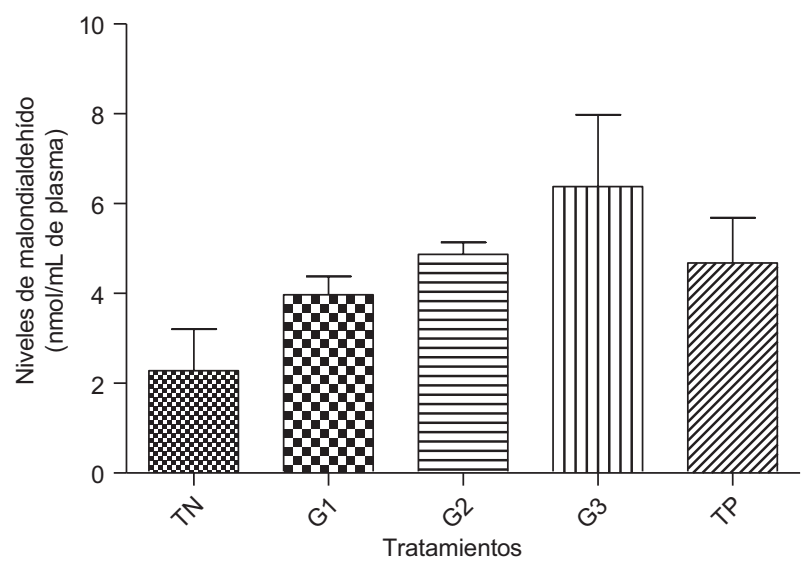

Fig. 3. Niveles de malondialdehído/mL en plasma de sangre periférica humana expuesta a glifosato II (Atanor ${ }^{\circledR}$ ) durante 4 horas. $\mathrm{TN}=$ Testigo negativo, $\mathrm{G} 1=37.5 \mu \mathrm{g} /$ $\mathrm{mL}, \mathrm{G} 2=75 \mu \mathrm{g} / \mathrm{mL}$ y G3 $=112.5 \mu \mathrm{g} / \mathrm{mL}$ de la formulación comercial. TP = testigo positivo $\left(20 \mu \mathrm{M}\right.$ de $\left.\mathrm{H}_{2} \mathrm{O}_{2}\right)$. Prueba de Dunnett luego de realizar un análisis de la varianza $(\mathrm{p}>0.05)$

Las diferencias halladas no fueron estadísticamente significativas acorde al resultado obtenido mediante un análisis de la varianza. Sin embargo, hay una tendencia al incremento de los valores en correspondencia con el aumento de la concentración de glifosato II (Atanor $\left.{ }^{\circledR}\right)(\mathrm{r}=0.99), \mathrm{p}<0.001$; prueba de Pearson), como puede observarse en la figura 4.

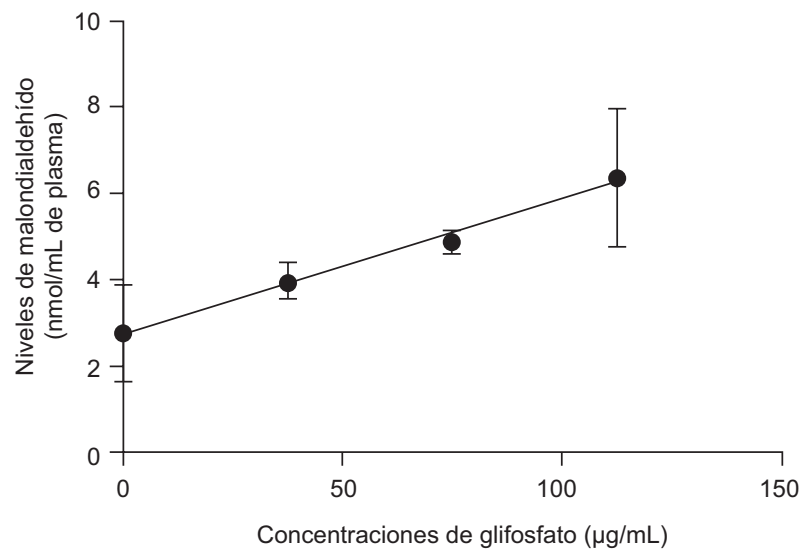

Fig. 4. Relación entre las concentraciones de malondialdehído cuantificadas mediante el ensayo de sustancias reactivas al ácido tiobarbitúrico y las concentraciones de glifosato II (Atanor $\left.{ }^{\circledR}\right)$. Coeficiente de correlación $r=0.99(p<$ 0.001, Prueba de Pearson) 
Por último, se encontró una correlación $\mathrm{r}=0.9590$ entre el daño al ADN cuantificado mediante el ensayo cometa y la evaluación del estado redox mediante TBARS (Pearson, $\mathrm{p}<0.05$; Fig. 5).

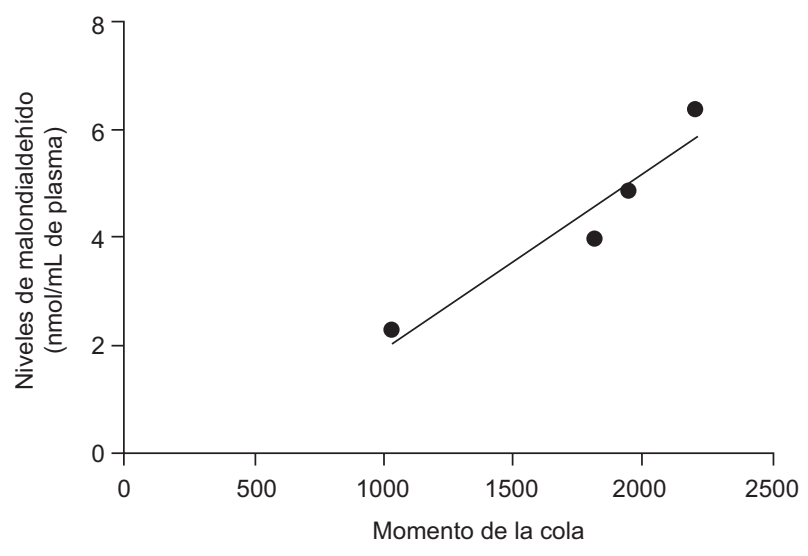

Fig. 5. Relación entre los niveles de malondialdehído cuantificadas mediante el ensayo de sustancias reactivas al ácido tiobarbitúrico y el daño al ADN expresado como el momento de la cola por el ensayo cometa en sangre periférica humana tras la exposición a tres concentraciones de glifosato II (Atanor $\left.{ }^{\circledR}\right)$. Coeficiente de correlación $\mathrm{r}=0.9590, \mathrm{p}<0.05$, prueba de Pearson

\section{DISCUSIÓN}

La relevancia del estudio de las formulaciones comerciales radica en que el ingrediente activo puede tener un efecto aditivo e incluso sinérgico al interactuar con coadyuvantes y demás sustancias químicas que forman parte de la solución que se comercializa (Marc et al. 2002, 2004, Dimitrov et al. 2006, Šiviková y Dianovskỳ 2006).

Son pocos los trabajos publicados en los que se han realizado ensayos de genotoxicidad in vitro en leucocitos de sangre periférica humana. Lioi et al. (1998) evaluaron el efecto de varios pesticidas incluyendo el glifosato como principio activo, mediante los ensayos de aberraciones cromosómicas e intercambio de cromátidas hermanas. Estos autores encontraron que concentraciones de $8,5,17 \mathrm{y}$ $51 \mu \mathrm{M}$ son capaces de aumentar significativamente el porcentaje de aberraciones y la frecuencia de intercambios. A su vez, estudiaron la actividad de la enzima G6PD, que se observó aumentada tras la aplicación de las concentraciones de glifosato anteriormente mencionadas. Mladinic et al. (2009) realizaron estudios de genotoxicidad y estrés oxidante del glifosato puro en concentraciones que oscilaron entre 0.5 y $580 \mu \mathrm{g} / \mathrm{mL}$, tanto con la adición de activación metabólica como sin ésta. Cuantificaron la lipoperoxidación mediante TBARS y la capacidad total antioxidante (TAC). Además utilizaron el ensayo cometa y analizaron la inestabilidad nuclear y cromosómica mediante FISH. Hallaron que sólo la dosis más alta fue capaz de incrementar estadísticamente todos los parámetros estudiados en las distintas técnicas. A diferencia de lo encontrado por estos autores, en este trabajo se observó un aumento en la fragmentación del ADN (mediante el ensayo cometa) y un incremento de la lipoperoxidación, con concentraciones entre $5 \mathrm{y}$ 15 veces menores, lo que demuestra nuevamente la controversia de los resultados en torno a la genotoxicidad de este plaguicida y en la determinación del estado anterior al oxidante.

Monroy et al. (2005) evaluaron el potencial genotóxico del glifosato puro en líneas celulares humanas (HT1080 y GM38) mediante el ensayo cometa y hallaron que concentraciones de 4.5 a $6.5 \mathrm{mM}$ incrementan significativamente el daño en el ADN, mientras que una solución $4 \mathrm{mM}$ de este compuesto no provocó aumento significativo respecto al testigo negativo. Los resultados encontrados en este trabajo difieren con el anterior ya que se observó que concentraciones aproximadamente 10 veces menores a la más baja $(0.22,0.44$ y $0.66 \mathrm{mM})$ produjeron daños significativos en el ADN. Mañas et al. (2009 a, b) utilizaron una línea celular de laringocarcinoma humano (Hep-2) para estudiar la genotoxicidad del glifosato puro y su principal metabolito, el ácido amino metil fosfónico (AMPA) a concentraciones de 3 a $7.5 \mathrm{mM}$ y de 2.5 a $7.5 \mathrm{mM}$, respectivamente, y encontraron evidencia para afirmar que todas las concentraciones evaluadas mediante el ensayo cometa produjeron un aumento significativo del daño en el material genético (excepto $2.5 \mathrm{mM}$ de AMPA, cuyo incremento no fue significativo respecto al testigo negativo). En este trabajo se utilizaron concentraciones de hasta 10 veces inferiores, lo que concuerda con lo realizado previamente por estos autores.

La empresa Atanor ${ }^{\circledR}$ recomienda el uso de su formulación comercial glifosato II en volúmenes que oscilan entre 2 y $6 \mathrm{~L} / \mathrm{ha}$, de acuerdo con el tipo de maleza que el agricultor desee combatir. La concentración de glifosato del producto comercial que se utilizó en este trabajo es de $210 \mathrm{mM}$, aproximadamente. La dilución que se debe realizar de este compuesto depende del tipo de aplicación que 
se lleve a cabo. En caso de que estas sean aéreas, la empresa recomienda el uso de 15 a 30 L finales, por lo que la concentración de glifosato II Atanor ${ }^{\circledR}$ que es pulverizado ronda los $37.33 \mathrm{mM}$, una concentración que es entre 56 y 170 veces superior a las distintas dosis evaluadas en este trabajo.

De acuerdo con los resultados obtenidos, se halló una correlación entre el aumento de la lipoperoxidación y la fragmentación de ADN medida como el momento de la cola, por lo que estimamos que el estrés oxidante podría ser uno de los principales factores que estarían alterando el funcionamiento normal de las células, entendiéndose a este proceso como la principal consecuencia de una exposición a glifosato.

Marc et al. $(2002,2004)$ llevaron a cabo estudios en embriones de erizo de mar (Sphaerechinus granularis) que determinaron que Roundup ${ }^{\circledR}$ es capaz de provocar una disfunción en el ciclo celular al retrasar la unión ciclina $\mathrm{B} / \mathrm{CDK} 1$ e incluso inhibir la síntesis de esta ciclina, resaltando la importancia de las formulaciones comerciales al concluir que los ingredientes activos y los coadyuvantes actuarían de manera sinérgica. A su vez, cabe resaltar que los reguladores del ciclo celular son universales, lo que aumenta la relevancia del estudio realizado por estos autores. Una posible explicación a lo que se observó en la investigación que aquí se reporta es que la formulación comercial que se estudió podría estar actuando del mismo modo que Roundup ${ }^{\circledR}$ en embriones de erizo de mar, es decir, inhibiendo la unión ciclina $\mathrm{B} / \mathrm{CDK} 1$ necesaria para el progreso del ciclo celular. Una desregulación de las proteínas involucradas en este proceso podría llevar a una inestabilidad genómica que a su vez, podría provocar los efectos observados mediante el ensayo cometa en el presente trabajo.

Si bien hasta hace algunos años se cuestionó la genotoxicidad potencial del herbicida glifosato, fundamentalmente desde sectores involucrados con la producción de alimentos, o por supuesto desde la propia industria, en la actualidad existe suficiente evidencia que demuestra que este herbicida no es tan inocuo como inicialmente se señaló. De hecho, a comienzos del año 2015, la IARC clasificó al glifosato en la categoría 2A ("probablemente carcinógeno para el ser humano"), reconociendo que existe una "fuerte" evidencia de la capacidad genotóxica del herbicida glifosato. Si bien aún no está completamente dilucidado, una de las posibles causas del daño genético causado por la exposición a glifosato, podría ser el estrés oxidante, tal y como lo sugieren los resultados hallados en el presente trabajo.

\section{REFERENCIAS}

Aiassa D., Mañas F., Bosch B., Gentile N., Bernardi N. y Gorla N. (2012). Biomarcadores de daño genético en poblaciones humanas expuestas a plaguicidas. Acta Biol. Colomb. 17 (3), 485-510.

Astiz M., de Alaniz J.T. y Marra C.A. (2009). The impact of simultaneous intoxication with agrochemicals on the antioxidant defense system in rat. Pestic. Biochem. Phys. 94 (2-3), 93-99.

DOI: 10.1016/j.pestbp.2009.03.005

Bolognesi C. (2003). Genotoxicity of pesticides: a review of human biomonitoring studies. Mutat. Res. 543 (3), 251-272.

DOI: $10.1016 / \mathrm{S} 1383-5742(03) 00015-2$

Brendler-Schwaab S.Y., Schmezer P., Liegibel U., Weber S., Michalek K., Tompa A. y Pool-Zobel B.L. (1994). Cells or different tissues for in vitro and in vivo studies in toxicology: compilation of isolation methods. Toxicol. In Vitro. 8 (6), 1285-1302. DOI: 10.1016/0887-2333(94)90122-8

Buege J. y Aust S. (1978). Microsomal lipid peroxidation. Method. Enzymol. 52, 302-310. DOI: 10.1016/S0076-6879(78)52032-6

De Marini D., Lentas J. y Brockman E. (1989). Utility of short-term tests for genetic toxicity. Cell. Biol. Tox. 5 (2), 189-200.

DOI: $10.1007 /$ BF00122652

De Sousa Sá O.M., Fontana Lopes N.N., Seixas Alves M.T., Lalla R.V., Vilela Oliva M.L. y Monteiro Caran E.M. (2013). Glycine supplementation reduces severity of chemotherapy-induced oral mucositis in hamsters. Nat. Sci. 5 (9), 972-978. DOI: 10.4236/ns.2013.59118

Di Fiori E., Pizarro H., Afonso M. y Cataldo D. (2012). Impact on the invasive mussel Limnoperma fortunei on glyphosate concentration in water. Ecotoxicol. Environ. Saf. 81, 106-113. DOI: 10.1016/j.ecoenv.2012.04.024

Dimitrov B.D., Gadeva P.G., Benova D.K. y Bineva M.V. (2006). Comparative genotoxicity of the herbicides Roundup, Stomp and Reglone in plant and mammalian test systems. Mutagenesis 21 (6), 375-382.

DOI: $10.1093 /$ mutage/gel044

FAO (2013). Aumenta la superficie de soja sembrada en Argentina. Food and Agricultural Organization [en línea]. http://www.fao.org/agronoticias/agro-noticias/ detalle/es/?dyna_fef[uid] $=161730$ 30/5/2013

Freshney R.I. (2000). Culture of animal cells: A manual of basic technique. J. Wiley. $4^{\circ}$ edición. Nueva York, EUA, 577 pp.

GEA (2013). Mejores rindes en zona núcleo compensan la caída del norte y permiten estimar más producción de soja. Estimación mensual nacional GEA - Guía Estratégica para el Agro. Guía Estratégica para el Agro. 
Año V (45) - [en línea] http://bcr.com.ar/GEA\%20Archivos \%20Diarios/Informes/Informe $\% 20$ especial $\% 20$ 045\%202013_05_13.pdf 5/5/2013

IARC (1991). Occupational exposure in insecticide application and some pesticides. International Agency for Research on Cancer. IARC Monogr Eval Carcinog Risks Hum. Lyon. 53, 179-250.

Lioi M.B., Scarfi M.R., Santoro A., Barbieri R., Zeni O., Di Berardino D. y Ursini, M.V. (1998). Genotoxicity and oxidative stress induced by pesticide exposure in bovine lymphocyte cultures in vitro. Mutat. Res. 403 (1-2), 13-20. DOI: 10.1016/S0027-5107(98)00010-4

Mañas F., Peralta L., Raviolo J., García Ovando H., Weyers A., Ugnia L., González Cid M., Larripa I. y Gorla N. (2009a). Genotoxicity of glyphosate assessed by the comet assay and cytogenetics tests. Environ. Toxicol. Phar. 28 (1) 37-41. DOI: 10.1016/j.etap.2009.02.001

Mañas F., Peralta L., Raviolo J., García Ovando H., Weyers A., Ugnia L., González Cid M., Larripa I. y Gorla N. (2009b). Genotoxicity of AMPA, the environmental metabolite of glyphosate, assessed by the Comet assay and cytogenetic tests. Ecotox. Environ. Safe. 72 (3), 834-837. DOI: 10.1016/j.ecoenv.2008.09.019

Marc J., Mulner-Lorillon O. y Bellé R. (2004). Glyphosatebased pesticides affect cell cycle regulation. Biol. Cell. 96 (3), 245-249. DOI: 10.1016/j.biolcel.2003.11.010

Marc J., Mulner-Lorillon O., Boulben S., Hureau D., Durand G. y Bellé R. (2002). Pesticide roundup provokes cell division dysfunction at the level of CDK1/Cyclin B activation. Chem. Res. Toxicol. 15 (3), 326-331. DOI: $10.1021 / \mathrm{tx} 015543 \mathrm{~g}$

Marcinčák S., Sokol J., Turek P., Różaňska H., Dičáková Z., Máté D., Popelka P. y Korim P. (2003). Comparative evaluation of analytical techniques to quantify malondialdehyde in broiler meat. Bull. Vet. Inst. Pulawy. 47, 491-496.
Mladinic M., Berend S., Vrdoljak A.L., Kopjar N., Radic B. y Zeljezic D. (2009). Evaluation of genome damage and its relation to oxidative stress induced by glyphosate in human lymphocytes in vitro. Environ. Mol. Mutagen. 50 (9), 800-807. DOI: 10.1002/em.20495

Monroy C.M., Cortés A.C., Sicard D.M. y Groot de Restrepo H. (2005). Citotoxicidad y genotoxicidad en células humanas expuestas in vitro a glifosato. Biomedica 25 (3), 335-345.

DOI: 10.7705/biomedica.v25i3.1358, 335-345.

PRISM (1997). GraphPad Software, Inc., San Diego, CA, EUA.

Sailaja N., Chandrasekhar M., Rekhadevi P.V., Mahboob M., Rahman M.F., Vuyyuri S.B., Danadevi K., Hussain S.A. y Grover P. (2006). Genotoxic evaluation of workers employed in pesticide production. Mutat. Res. 609 (1), 74-80. DOI: 10.1016/j.mrgentox.2006.06.022

Singh N., McCoy M.T., Tice R.R. y Schneider E.L. (1988). A simple technique for quantification of low levels of DNA damage in individual cells. Exp. Cell Res. 175 (1), 184-191.

Šiviková K. y Dianovskỳ J. (2006). Cytogenetic effect of technical glyphosate on cultivated bovine peripheral lymphocytes. Int. J. Hyg. Environ. Health. 209 (1), 15-20. DOI: 10.1016/j.ijheh.2005.07.005

INSHT (2000). Control biológico de la exposición a genotóxicos: Técnicas Citogenéticas. Instituto Nacional de Seguridad e Higiene en el Trabajo. Ministerio del Trabajo y Asuntos Sociales, España. NTP (Nota Técnica de Prevención). Barcelona, España, 5 pp.

Vila-Aiub M.M., Vidal R.A., Balbi M.C., Gundel P.E., Trucco F. y Ghersa C.M. (2008). Glyphosate-resistant weeds of South American cropping systems: an overview. Pest. Manag. Sci. 64 (4), 366-371.

DOI: $10.1002 /$ ps. 1488 